\title{
Can we migrate COVID-19 spreading risk?
}

\author{
Qingyan Chen (凶) \\ School of Mechanical Engineering, Purdue University, West Lafayette, IN 47907, USA
}

(C) Higher Education Press 2020

\begin{abstract}
It is well recognized that Severe Acute Respiratory Syndrome Coronavirus 2 (SARS-CoV-2) virus could be spread through touch and large droplets. However, we may have under-estimated the disease transmission by small droplets or aerosols that contain SARS-CoV-2 virus. Social distancing in public transport vehicles, such as airplanes, is not feasible. It is also not possible to wear masks in restaurant. This paper recommended wearing masks in airplanes and use partition screens in the middle of a table in a restaurant to reduce the infection caused by SARS-CoV-2 virus. Advanced ventilation systems, such as personalized ventilation and displacement ventilation, are strongly recommended for transport vehicles and buildings.
\end{abstract}

Keywords Airborne transmission, Ventilation, Masks, Partitions

COVID-19 or SARS-CoV-2 has infected over four million people and has taken 280000 lives as of May 9, 2020. The pandemic has also halt the economy in the world. Everyone is seeking advice how to have a new normal life. This short article is to assist the public in protecting themselves in the new normal life by proposing a few measures in transport vehicles and buildings.

We started in 2004 studying airborne infectious disease transmission through the FAA Center of Excellence for Airliner Cabin Environment Research (ACER) under congressional mandate through public law 108-76. The author, Qingyan Chen, served as a co-founding principal director for ACER from 2004 to 2010. ACER consisted of a group of professionals representing different disciplines, such as mechanical engineers, public health scientists, chemists, materials engineers, environmental engineers, and electrical engineers. One of the key research projects

Received May 9, 2020

E-mail: yanchen@purdue.edu

Special Issue-Bioaerosol, Environment and Health (Responsible Editors: Can Wang, Jungho Hwang, Jingkun Jiang \& Maosheng Yao) was "Infectious Disease Transmission in Airliner Cabins" led by Chen (Chen et al., 2012). Given the experience and expertise, Chen has become a go-to source for commentary and advice by media in the past few weeks on how to curb the spread of SARS-CoV-2, particularly on transport vehicles and buildings. Our work has been quoted by top-tier media such as Aljazeera, AP, BBC, Business Insider, BuzzFeed, Cheddar.tv, CNN, Fast Company, Forbes, Fox News, Los Angeles Times, Sydney Morning Herald, The Washington Post and USA Today. Our effort was to offer our thoughts on what all of us need to do to keep SARS-CoV-2 at bay.

1) Airborne spread of SARS-CoV-2 virus. Experts so far cannot agree if SARS-CoV-2 transmission could be airborne (Lewis, 2020), via small droplets or aerosols, although research has shown the risk. Early studies found that all the masks used by SARS-CoV-2 patients in some hospitals, contained SARS-CoV-2 virus. Recent study (Liu et al., 2020) found SARS-CoV-2 virus RNA in indoor air of two hospital. It is very difficult to sample air and detect the virus as the concentration is generally low. This proved that droplets from coughing, speaking and even breathing contain the virus. However, many believe that SARS-CoV2 transmission is only by touch and large droplets.

If large droplets contain the virus, the small ones should, too. The only difference is that large droplets may contain more virus than small ones. Small droplets, or aerosols, can be airborne and could make someone sick if the person is exposed in an indoor space for a long time. Now other studies (Bourouiba, 2020) have also shown that droplets can be transported to a distance beyond two meters (six feet) and that small droplets can be airborne for a few seconds to a few hours, depending on the droplet size (Gupta et al., 2012).

2) Practical measures to reduce SARS-CoV-2 infection. If SARS-CoV-2 virus is airborne, it would be similar to SARS virus (van Doremalen et al., 2020). Our SARS study found that during a four-hour flight, about $20 \%$ of passengers would be infected if one SARS patient is on the plane (Olsen et al., 2003) and SARS virus was airborne. By assuming that the patient still produced the same amount of 
virus and did not wear a mask but everyone else on the plane wore an N95 mask, our research showed that none of the passengers would become sick. Such a scenario is unlikely real, but it indicates the importance of wearing a mask. With everybody wearing a mask, social distancing could be reduced, although we would need more research to provide a concrete answer as to how much. Thus, we would recommend people wearing masks in all public indoor spaces, such as public transport vehicles, schools, offices, factories, stores, etc.

Of course there are indoor spaces one can not wear a mask, such as restaurants and bars. It would be important to change ventilation systems or to install Plexiglas screens in the middle of a table or between customers. Figure 1 shows the droplet cloud that may contain SARS-CoV-2 virus with and without a screen in the middle of a table in a restaurant. The screen helps a lot in reducing the possible infection caused by droplet cloud coughed out by the person across the table.

In addition to masks and screens, advanced ventilation systems such as personalized ventilation systems (You et al., 2018) and displacement ventilation (Shi et al., 2020) are also effective in migrating the infection risk. By using airplane cabin as an example, clean air could be supplied at a lower temperature than the cabin air from individual air supply units underneath of the seats in front row as shown Fig. 2(a) (You et al., 2018). The buoyancy force from a passenger's body would generate a thermal plume that can bring the clean air from the lower part of the cabin to the breathing zone of the passenger. The contaminated air breathed out by the passenger would move to the upper part of the cabin due to the thermal plume and be extracted at the ceiling level. Figure 2(b) illustrates that the personalized ventilation system does not mix air in the cabin. Every passenger inhales in clean air and the contaminated air exhaled out by the passenger is removed though outlets without mixing. This system can greatly reduce infection risk. Unfortunately, such a system has not been used by any commercial airplane manufacturers but it could be used in the near future to mitigate SARS-CoV-2 risk.

Similar concept can be used for buildings where seats may not be fixed. For example, Fig. 3 shows a classroom uses displacement ventilation. Cool air is supplied from the four corners of the room at low air velocity. The warm bodies of the students in the room can generate thermal plumes that bring the clean air from the lower part of the room to the breathing zone. The thermal plumes will further bring the $\mathrm{CO}_{2}$ exhaled out by the students to the upper part of the room and eventually extracted at the

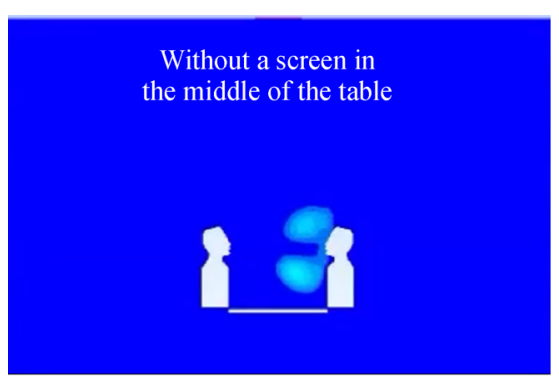

(a)

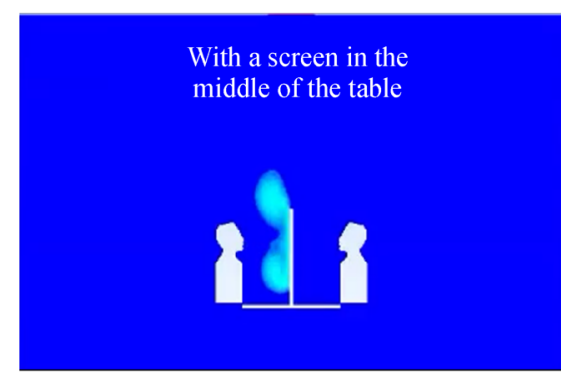

(b)

Fig. 1 Transport of droplet cloud coughed out by a diner (left) to the other diner across a table (right): (a) without a screen and (b) with a screen.

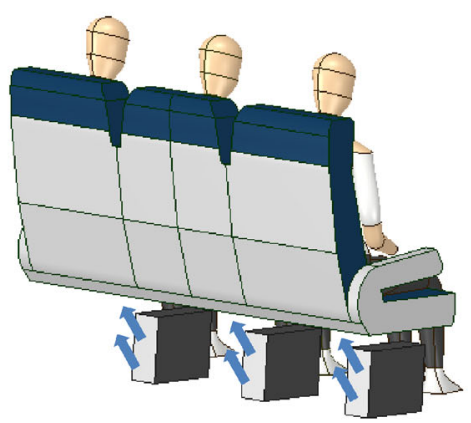

(a)

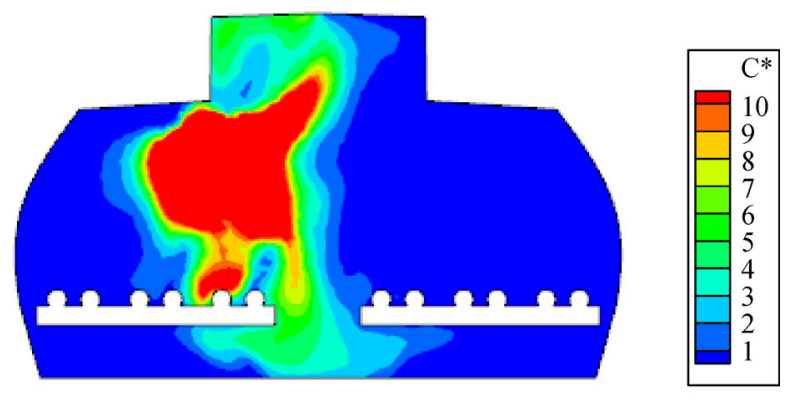

(b)

Fig. 2 Schematic of the personalized ventilation system: (a) air flow from the lower part to the ceiling level of an aircraft cabin; (b) Normalized distribution of small droplets with 1 um by a passenger sit on an aisle seat. 


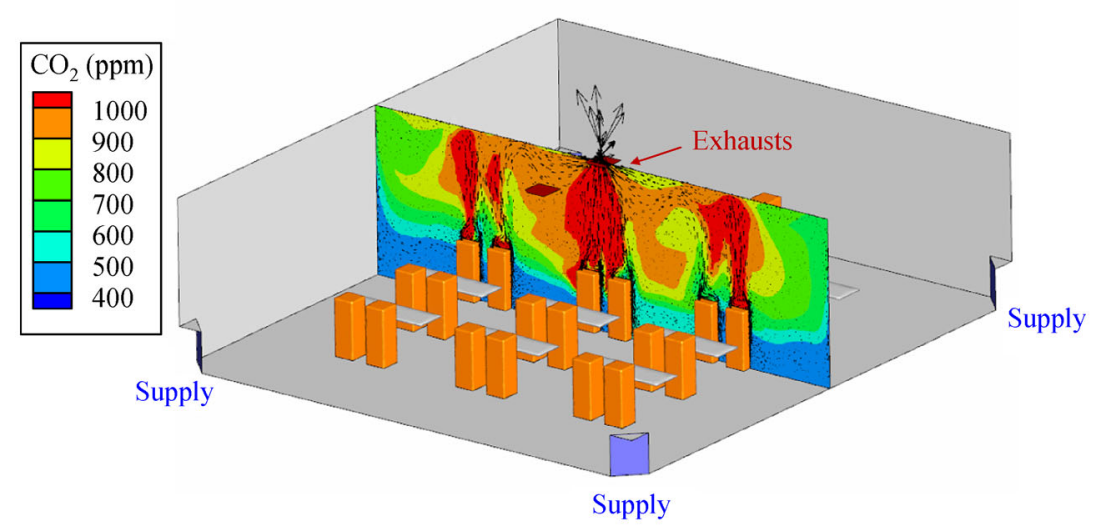

Fig. 3 A classroom with displacement ventilation that does not mix air so it can minimize infectious disease transmission.

ceiling outlet. The concept is different from mixing ventilation we normally see in buildings. The air with displacement ventilation does not mix so that the risk of inhaling airborne infectious disease virus from a neighboring student can be greatly reduced. Displacement ventilation has been used in buildings in the United States and we have developed a design guide for it (Chen and Glicksman, 2003).

For an air traveler, virus transmission occurs not only in an airplane cabin but in the entire door-to-door process, including taking public transport from home to airport, checking in at an airport counter, being screened for safety, waiting in a lounge, boarding an airplane, deplaning, picking up checked luggage, and taking public transport to your destination. Social distancing is important, but it is impossible in some cases, such as in a bus, a subway train, or an airplane cabin. Thus, it is critical to wear a mask from door to door.

Because we stay in offices, factories, schools, etc. for a long time, everyone should wear a mask to reduce infection risk although the SARS-CoV-2 virus concentration in indoor air may not be very high. Long time exposure under low virus concentration impose considerable risk. In addition, air-conditioning systems should run with $100 \%$ outside air to prevent possible crosscontamination between spaces, since outdoor air is unlikely to contain SARS-CoV-2 virus.

This paper used an airplane, a restaurant, and a classroom to illustrate our idea, it is not universal. Business owners should carefully examine whether their business is vulnerable to the four possible infection routes of SARSCoV-2: 1) direct contact, or indirect contact through fomite (for example, via a cup); 2) large droplets; 3) small airborne droplets, and 4) fecal-oral transmission. The four routes of transmission, and respective solutions, depend very much on business type.

In conclusion, SARS-CoV-2 virus could be airborne so it is challenging to prevent one from infection. Wearing mask would help as it can reduce the exposure to SARS$\mathrm{CoV}-2$ virus in air. Advanced ventilation systems should also be used to further migrate the infection risk.

Acknowledgements The author would like to thank his former and current $\mathrm{Ph}$.D. students, Jitendra Gupta, Ruoyu You, and Zhu Shi, for their significant contributions to this paper.

\section{References}

Bourouiba L (2020). Turbulent gas clouds and respiratory pathogen emissions: Potential implications for reducing transmission of COVID-19. JAMA, 323(18): 1837-1838

Chen Q, Glicksman L R (2003). System Performance Evaluation and Design Guidelines for Displacement Ventilation. New York: ASHRAE

Chen Q, McDevitt J J, Gupta J K, Jones B W, Mazumdar S, Poussou S B, Spengler J D (2012). Infectious disease transmission in airliner cabins. National Air Transportation Center of Excellence for Research in the Intermodal Transport Environment (RITE), Report No. RITE-ACER-CoE-2012-01

Gupta J K, Lin C H, Chen Q (2012). Risk assessment for airborne infectious diseases in aircraft cabins. Indoor Air, 22(5): 388-395

Lewis D (2020). Is the coronavirus airborne? Experts can't agree. Nature, 580(7802): 175

Liu Y, Ning Z, Chen Y, Guo M, Liu Y L, Gali N K, Sun L, Duan Y S, Cai J, Westerdahl D, Liu X J, Xu K, Ho K F, Kan H D, Fu Q Y, Lan K (2020). Aerodynamic analysis of SARS-CoV-2 in two Wuhan hospitals. Nature, doi: 10.1038/s41586-020-2271-3

Olsen S J, Chang H L, Cheung T Y Y, Tang A F Y, Fisk T L, Ooi S P L, Kuo H W, Jiang D D S, Chen K T, Lando J, Hsu K H, Chen T J, Dowell S F (2003). Transmission of the severe acute respiratory syndrome on aircraft. New England Journal of Medicine, 349(25): 2416-2422

Shi Z, Lai D, Chen Q (2020). Performance evaluation and design guide for a coupled displacement-ventilation and passive-chilled-beam system. Energy and Building, 208: 109654 
van Doremalen N, Bushmaker T, Morris D H, , Holbrook M G, Gamble A, Williamson B N, Tamin A, Harcourt J L, Thornburg N J, Gerber S I, Lloyd-Smith J O, de Wit E, Munster V J (2020). Aerosol and surface stability of SARS-CoV-2 as compared with SARS-CoV-1.
New England Journal of Medicine, 382(16): 1564-1567

You R, Zhang Y, Zhao X, Lin C H, Wei D, Liu J, Chen Q (2018). An innovative personalized displacement ventilation system for airliner cabins. Building and Environment, 137: 41-50 